\title{
Percursos das transformações da teoria e da validação do conhecimento nas ciências humanas: do falsificacionismo de Popper à teoria de valor de Rickert
}

\author{
Miranda, Marcelo Henrique Gonçalves de ${ }^{1}$ \\ Pensam os sábios, com razão, que os homens de \\ todas as épocas imaginavam saber o que era bom \\ ou mau, louvável ou condenável. Mas é um \\ preconceito dos sábios acreditarem que hoje o \\ sabem melhor que em qualquer outra época
}

Nietzsche.

\section{Resumo}

O presente artigo tem como finalidade, de forma geral, retratar alguns aspectos do debate epistemológico sobre as condições de validade na produção do conhecimento científico para as ciências humanas via questões que dizem respeito às ciências nomotéticas e sobre as ciências ideográficas. Busca-se a) mapear os percursos assumidos na construção desses dois campos de saber relacionando-os às implicações das tradições empirista e racionalista; b) problematizar a relação entre o sujeito e o objeto da pesquisa; e c) sublinhar-se-á os aspectos que a teoria do conhecimento assumiu dentro do falsificacionismo de Popper e da teoria do valor de Rickert na construção do campo de conhecimento das ciências humanas.

Teoria do Conhecimento. Ciências Nomotéticas. Ciências Ideográficas. Teoria do Valor.

\section{Resumen}

Este artículo se dedica, en general a retratar algunos aspectos del debate epistemológico sobre las condiciones de validez en la producción de conocimiento científico para las humanidades a través de temas relacionados a las ciencias nomotéticas y las ciencias ideográficas. Se busca a) mapear las rutas realizadas en la construcción de estos dos campos del conocimiento los relacionando a las implicaciones del las tradiciones empirista y racionalista; b) examinar la relación entre el sujeto y el objeto de la investigación; y c) enfatizar los aspectos que la teoría del conocimiento asumió dentro del falsificacionismo de Popper y de la teoría del valor de Rickert en la construcción del campo de conocimiento de las ciencias humanas.

Teoria del Conocimiento. Ciencias Nomotéticas. Ciencias Ideográficas. Teoría del Valor.

\footnotetext{
${ }^{1}$ Doutor em Sociologia, professor adjunto da Universidade Federal de Pernambuco e-mail: <mm.marcelohenrique@yahoo.com.br>
} 


\section{Introdução}

O presente artigo tem como finalidade, de forma geral, retratar alguns aspectos do debate epistemológico sobre as condições de validade na produção do conhecimento científico para as ciências humanas via questões que dizem respeito às ciências nomotéticas, isto é, ciências que buscam estabelecer regras gerais na explicação dos fenômenos e que podem ser reproduzidos em experimentos; e sobre as ciências ideográficas, ou seja, ciências que se preocupam em estudar o singular, o único e os fenômenos que não podem ser reproduzidos por meio de experimentos. Busca-se mapear os percursos assumidos na construção desses dois campos de saber relacionando-os às implicações das tradições empirista e racionalista; problematizar a relação entre o sujeito e o objeto da pesquisa; e de uma maneira específica, sublinhar-se-á os aspectos que a teoria do conhecimento assumiu dentro do falsificacionismo de Popper (1902 - 1994) e da teoria do valor de Rickert (1863-1936). A princípio destacaremos algumas ideias de Kant (1724-1804) sobre a filosofia do conhecimento que são retomadas no pensamento de Rickert.

\section{Duas diferentes tradições de conceber a teoria do conhecimento científico}

Segundo Bento (1977), Kant, em uma das suas obras clássicas: Crítica da Razão Pura, considera que o conhecimento é obtido por meio de julgamento objetivo da ciência ou do senso comum. Nesse percurso, o conhecimento é engendrado por meio da experiência, mas tal construção só ganha sentido ou percepção via categorias a priori que ordenam conceitualmente a percepção da experiência para ser entendida. Portanto,

A mente não faz simplesmente e passivamente "gravar" senso impressões. Espaço e Tempo são (a priori) as formas nas quais a experiência perceptual é ordenada. Anteriormente disso, os julgamentos perceptuais adquirem objetividade. Adquire os status do julgamento sobre a existência e a natureza da realidade exterior. (BENTO, 1977, p. 102). 
É importante destacar que essa teoria do conhecimento, por meio do julgamento objetivo do conhecimento científico ou do senso comum, servirá de base para se problematizar: a) a relação entre sujeito de pesquisa das ciências humanas (kulturwissenschaften) com o seu objeto de estudo, no caso outro ser humano, e o sujeito das ciências naturais com o seu objeto de estudo, ou seja, algum fenômeno da natureza; e b) a não neutralidade do pesquisador das ciências humanas como impossibilidade dessa ciência adquirir o mesmo estatuto das ciências naturais. Tais problematizações serão desenvolvidas mais adiante.

Com essa concepção da teoria do conhecimento, Kant busca ultrapassar os debates entre as tradições Empiristas e Racionalistas. Se por um lado, o Empirismo, de tradição inglesa (nasce em Locke 1632-1704), valoriza que todo o processo do conhecer, do saber e do agir é aprendido pela experiência, pela tentativa e erro, compreendido aqui por Abbagnano como:

a diretriz filosófica que faz apelo à experiência como critério ou norma da verdade e que, por isso, assume a palavra "experiência". Em geral, tal diretriz se caracteriza pelos traços seguintes: a) nega o caráter absoluto da verdade ou, ao menos, da verdade que é acessível ao ser humano; b) reconhece que toda verdade pode e deve ser posta à prova, logo, eventualmente modificada, corrigida ou abandonada. (1982, p. 308).

Por ouro lado, no Racionalismo (de Descartes, 1596-1650 a Espinosa, 16321677; e Leibniz, 1646-1716) impera a forma de raciocínio dedutivo, na qual há a classificação do mundo pelo procedimento da razão determinando crenças e técnicas. Conhecimento, nesse viés, é, assim derivado aprioristicamente de axiomas auto evidentes ou racionalmente demonstráveis. (ABBAGNANO, 1982; OUTHWAITE \& BOTTOMORE, 1996).

Exposto o debate entre Empirismo e Racionalismo que constituía o campo de produção do conhecimento nos séculos XVII e XVIII, vejamos a partir desse contexto as principais características da teoria do conhecimento em Popper e posteriormente em Rickert predominantes no século XX e suas contribuições para produção do conhecimento das ciências humanas. 


\section{O falsificacionismo de Popper: A ciência progride por conjecturas e refutação}

Karl Popper (1902-1994) tem por objetivo contestar o Positivismo Lógico ou Empirismo Lógico do Ciclo de Viena que em linhas gerais foi uma forma extrema de empirismo, alegando que as teorias deveriam ser válidas por meio dos fatos adquiridos na observação (BENTO, 1977; CHALMERS, 2000; GIDDENS, 1998).

Pensando na produção do conhecimento e no método das ciências humanas, Popper, na sua filosofia da ciência denominada de falsificacionismo, admite que a observação seja orientada por teorias que fornecem categorias a priori na constatação da experiência. No entanto, o autor traz à baila na sua filosofia da ciência que as teorias não podem ser estabelecidas como verdadeiras ou provavelmente verdadeiras a partir da evidência observativa. Para Popper

As teorias são interpretadas como conjecturas especulativas ou suposições criadas livremente pelo intelecto humano no sentido de superar problemas encontrados por teorias anteriores e dar uma explicação adequada do comportamento de alguns aspectos do mundo ou do universo (CHALMERS, 2000, p. 64).

A ideia defendida por Popper diz respeito a que uma vez que as teorias especulativas são propostas devem ser testadas implacavelmente por observação e experimento. Não se pode ter certeza da veracidade das teorias, diante disso, opta-se por testes para tentar refutar as hipóteses ou ver a sua capacidade de resistência a esses testes. As teorias que não resistem aos testes de observação, e experimento, devem ser descartadas.

Em seu livro: Lógica das Ciências Sociais constam vinte sete teses sobre a teoria do conhecimento, no entanto, destacamos a sexta por ser considerada, por alguns teóricos (BENTO, 1977; CHALMERS, 2000; GIDDENS, 1998) como a principal. Nessa tese Popper afirma materializando o falsificacionismo que:

a) O método das ciências sociais, como aquele das ciências naturais, consiste em experimentar possíveis soluções para certos problemas; os problemas com os quais iniciam-se nossas investigações e aqueles que surgem durante a investigação. As soluções são propostas e criticadas. Se uma solução proposta não está aberta a uma crítica pertinente, então é excluída como não científica, embora, talvez, apenas temporariamente. 
b) Se a solução tentada está aberta a críticas pertinentes, então tentamos refutá-la, pois toda crítica consiste em tentativas de refutação.

c) Se uma solução tentada é refutada, através do nosso criticismo, fazemos outra tentativa.

d) Se ela resiste à crítica, aceitamo-la temporariamente; e a aceitamos, acima de tudo, como digna de ser discutida e criticada mais além.

e) Portanto, o método da ciência consiste em tentativas experimentais para resolver nossos problemas por conjecturas que são controladas por severas críticas. É um desenvolvimento crítico consistente do método de 'ensaio e 'erro'.

f) A assim chamada objetividade da ciência repousa na objetividade do método crítico. Isto significa, acima de tudo, que nenhuma teoria está isenta do ataque da crítica; e mais ainda, que o instrumento principal da crítica lógica - a contradição lógica - é objetivo (POPPER, 1998, p. 15-16).

Na busca para exemplificar a tese de Popper, Chalmers nos indica abaixo um modelo para ilustrar tal pensamento se apoiando na lógica do falsificacionismo:

Um corvo, que não era preto, foi observado no local $x$ no momento $m$ " deduzir logicamente disto que "todos os corvos são pretos" é falso. Isto é, o argumento.

Premissa: um corvo, que não era preto, foi observado no local $x$ no momento $m$.

Conclusão: Nem todos os corvos são pretos. (CHAKMERS, 2000, pp. 64-65).

Assim, dentro da visão do falsificacionismo, algumas teorias podem se revelar falsa, e podem ser derrubadas, por meio de um apelo aos resultados da observação e do experimento. A lógica que apoia o falsificacionismo nos mostra que não é possível chegar leis e teorias universais por deduções lógicas, visto que proposições de observação singulares alteram ou podem sempre vir a alterar leis e teorias universais.

Nesse percurso, no campo da produção do conhecimento das ciências humanas, as situações específicas de cada cultura ou contexto histórico instituído como singular que são observáveis constituem a propriedade de refutar leis e teorias concebidas como universais. Assim, a crítica indutiva desestabiliza proposições teóricas mais gerais. 
Entretanto Giddens (1998) nos expõe dois limites em Popper. O primeiro limite, exposto também por Chalmers (2000), diz respeito à ênfase que Popper atribui à refutabilidade que repousa na relação mais próxima possível com a crítica da lógica indutiva. Para Popper, a lógica da produção do conhecimento científico por indução de leis torna a certeza impossível, apesar de fazermos muitos testes, podemos afirmar que por meio de um próximo teste é possível deixar de confirmar o conhecimento produzido. Desta forma, a validade das leis científicas jamais pode ser verificada conclusivamente e tal aspecto prejudicaria a própria constituição das ciências humanas como campo científico mesmo que tendo a suas especificidades.

O segundo limite está relacionado com a questão do desprezo da linguagem. Para Popper a terminologia teria como função a clareza e a ausência de ambiguidade nos testes rigorosos das teorias científicas. Ou seja, é como se os termos se constituíssem como uma relação de causa e efeito entre o sujeito emissor e o sujeito receptor da linguagem sem a possibilidade de outras interpretações ou "ruídos" nessas interpretações. Para Popper, as palavras mesmo sendo diferentes teriam de expressarem as mesmas ideias.

Nesse ponto, Popper não considerou a polissemia dos termos e próprio uso da linguagem, como fez a virada linguística para as ciências humanas, para se ter acesso à realidade e haver a inteligibilidade nas interações sociais. Ao desconsiderar a polissemia dos termos, esse procedimento termina aproximando Popper do Círculo de Viena que ele tanto alegou se diferenciar e da primeira fase de Wittgenstein que influenciou parte do Positivismo Lógico e que foi ultrapassada pela segunda fase de Wittgenstein sobre os jogos de linguagem.

Assim, verifica-se, sobretudo no campo de produção de conhecimento das ciências humanas, que vários indivíduos podem verbalizar um mesmo termo e esse ter significados distintos ao mesmo tempo que indivíduos diferentes podem falar termos distintos e eles terem o mesmo significado. Os termos são significantes vazios que ganham significados em decorrência do processo valorativo em que cada sujeito se encontra e das regras estabelecidas em cada contexto de interação. Ou seja, os significados dependem de contexto histórico, 
do tempo e espaço ao qual o indivíduo tem vivenciado sua experiência e das relações estabelecidas nas teias de significados e de valores materializadas por meio das socializações e das sociabilidades.

O que nos parece é que até o momento, a ênfase da tradição do falsificacionismo exposta aqui em Popper não questiona na relação sujeitoobjeto o processo de entendimento, o Verstehen, nem por parte do objeto que seria nas ciências do espírito ou da cultura (para usar termos neokantianos) o próprio ser humano, nem por parte do Verstehen relacionado ao pesquisador que busca compreender o que os indivíduos expressam.

Dessa maneira, percebe-se que há um período de transição entre explicações causa-efeitos gerais abundantes nas ciências da natureza e a questão do entendimento/compreensão (Verstehen) que posteriormente será problematizado nas ciências humanas. Para compreendermos melhor 0 processo de transição no campo da teoria do conhecimento tendo como referência a partida do método das ciências da natureza para o método da teoria do valor na constituição do método das ciências humanas por meio das contribuições de Heinrich Rickert, indicaremos algumas características do neokantismo ou do neocriticismo que estão na base epistemológica desse teórico.

\section{O Neokantismo}

Alguns teóricos (ABBAGNANO, 1982; BENTO, 1977; FERREIRA, 1999; DA MATA, 2006) nos expõe que a corrente filosófica do neokantismo se estabeleceu a partir de meados do século XIX na Alemanha, inicialmente hostil ao idealismo alemão, a todo tipo de metafísica e ao positivismo francês e inglês. Essa corrente filosófica voltou a destacar a distinção kantiana entre o mundo noumenal e o mundo do fenômeno.

Para Kant havia uma separação entre o mundo fenomênico aberto para a percepção; e o mundo noumenal (inteligível), ou seja, os dos métodos e conceitos do pensamento do conhecimento científico (BENTO, 1977, p.104).

Ao sublinhar essa distinção acima referida entre os mundos, os neokantianos consideraram que o mundo fenomênico é infinito/irracional, ao 
passo que o mundo noumenal é racional e finito. O ser humano ao categorizar ordena e limita o caos da realidade ao seu redor, registrando apenas o que pode apreender por suas categorias a priori e não existindo categorias não acontece a inteligibilidade, ou seja, não há possibilidade do mundo da vida ser acessado, classificado e transformado pelo cientista. O desafio dessas alegações está relacionado com a teoria do conhecimento científico que tem de transcender 0 mundo da vida.

Em relação à teoria do conhecimento científico, segundo Ferreira (1999), para os neokantianos, a ciência necessita encontrar princípios universais e não transitórios, para que ela possa reivindicar para si um status acima do mundo da vida.

\begin{abstract}
A reflexão epistemológica seria, então, uma alternativa de certeza, segurança, às disjunções deste presente que tende a se perder em excesso, em arte. Adiantando o nosso argumento: ao colocar entre parênteses a própria finitude do sujeito cognoscente, a reflexão epistemológica promovida pelos neokantianos da Escola de Baden esforça-se por construir uma área de segurança a partir da qual o mundo da vida possa ser acessado, classificado e transformado por um sujeito livre, posicionado acima da transitoriedade e excesso da vida moderna. (FERREIRA, 1999, p. 75).
\end{abstract}

Vale destacar que vários neokantianos tentaram dar respostas à problemática acima, isto é, entre a finitude do sujeito cognoscente e produção de conhecimento de princípios universais e não transitórios, além de abordarem questões relacionadas a diferenças ou a aproximações relativas às ciências da natureza e da cultura/espírito tais como: Wilhelm Dilthey, Georg Simmel, Heinrich Rickert. Contudo, concentrar-se-á apenas em Rickert, na sua teoria do valor e na contribuição de sua teoria para o campo de produção de conhecimento das ciências humanas, visto que se trata de um espaço restrito na confecção desse artigo.

\title{
4 Heinrich Rickert e a Teoria do Valor
}

O principal trabalho de Heinrich Rickert, Die Grenzen der naturwissenschaftlichen Begriffsbildung foi publicado pela primeira vez em 1902. 
Uma de suas principais realizações foi elaborar uma fundamentação no plano lógico-conceitual para as ciências culturais (kulturwissenschaften), ou seja, para as ciências humanas que deveriam estar de acordo com uma epistemologia e lógica existentes (DA MATA, 2006; OUTHWAITE, 1985).

Assim como outros neokantianos, Rickert traz a distinção entre ciências nomotéticas e ciências ideográficas, mas esta diferenciação se daria não por causa do objeto, pois o mundo é o mesmo tanto para as ciências da natureza como para as ciências culturais. A diferença está relacionada à metodologia específica que cada uma usa. Ou seja, "a mesma realidade se torna natureza se a consideramos do ponto de vista do geral, e se torna história, cultura se a consideramos do ponto de vista do especial e do individual, do específico" (DA MATA, 2006, p. 354).

Rickert ao afirmar que o mundo é o mesmo para as ciências naturais e para as ciências humanas contribuem para problematizar o estatuto das primeiras como sendo exclusivamente científico, pois a diferença estaria não no objetivo de estudo, mas sim no método de estudo. As ciências da natureza buscam explicações gerais que podem ter validadas sua produção de conhecimento por meio da repetição das experiências. Já nas ciências humanas a validade de seu conhecimento se dá pelo que há de específico, exclusivo, ou seja, o histórico que não pode ser repetido em laboratório.

Os métodos das ciências kulturwissenschaften são individualizados e estão referidos a valores, enquanto os das ciências naturwissenschaftlichen são generalizados

Nesta perspectiva, a diferença principal em relação às ciências da natureza não deveria ser buscada no plano material (nível dos objetos) aos quais umas e outras se devotam, mas nos procedimentos adotados, ou seja, plano formal (nível lógicoconceitual). O que se opõe ao "natural" não é o "espiritual", diz Rickert, mas o "histórico" (entendido aqui enquanto evento ou realidade singular.) (DA MATA, 2006, p. 349).

Portanto, nessa perspectiva, o que diferencia a ciência, de maneira geral, de outras formas de conhecimento e percepção da realidade é o fato que a ciência elabora conceitos. Da Mata (2006) nos expõe que para Rickert, o ser 
humano comum é distinto do indivíduo cientista porque este último tende a extrair - do agregado de conhecimentos que sirvam às necessidades imediatas do primeiro - daquele mesmo agregado, um sistema.

Dessa maneira, estes conceitos são os instrumentos ou, numa linguagem mais kantiana, são as categorias a priori que possibilitam apreender parte da realidade. Eles seriam sempre uma leitura da realidade, uma vez que é impossível obter a realidade em sua totalidade, pois a mesma é multifacetada e complexa e os conceitos nos permitem operacionalizar e reduzem a complexidade. Nessa perspectiva, o conhecimento produzido cientificamente é sempre inacabado, pois o pesquisador não tem como ter acesso à realidade na sua totalidade, uma vez que, via conceito, só se tem acesso à parte dessa realidade.

Assim, podemos alegar que o conceito seria um instrumento ao mesmo tempo em que seria o objetivo da teoria do conhecimento científico. O que, dessa maneira, permitiria exceder o mundo da vida por meio da transcendência conceitual que caracteriza o campo de conhecimento científico.

Da Mata (2006) nos traz a indagação sobre a ideia de conceito histórico exposta por Rickert visto que se a história foca sua pesquisa nas especificidades dos fenômenos o que permite afirmar que ela opera suas análises conceitualmente.

Assim, tal perspectiva depende da definição de categorias e ou conceito de entendimento e conceitos científicos que podem ser mais simples ou ser mais abstratas. É importante ressaltar que, para Kant, as categorias seriam mais abstratas do que os conceitos tais como as categorias de tempo e espaço que seriam maneiras de o ser humano ordenar o mundo.

Nesse caminho, Abbagnano expõe que para Kant, as categorias são os modos pelos quais se manifesta a atividade do intelecto, a qual consiste essencialmente

em ordenar diversas representações sob uma representação comum, isto é, em julgar. Elas são, portanto, as formas [...] em que o juízo se explica independentemente do seu conteúdo empírico. [...] as categorias são conceitos primitivos do intelecto puro e condicionam todo o conhecimento intelectual e a própria experiência; mas elas não se aplicam às coisas em si e o 
conhecimento que delas se vale (isto é, todo o conhecimento humano) não pode estender-se, portanto a tais "coisas em si" ou "númenos". As categorias são, todavia, condições da validade objetiva do conhecimento, isto é, do juízo em que o conhecimento se concretiza. Com efeito, um juízo é uma conexão entre representações. Mas tal conexão não é subjetiva, logo não vale só para o sujeito isolado que a efetua, mas é feita [...] segundo um modo, uma regra que é igual para todos e que, portanto, confere necessidade e objetividade àquilo a que se ligou na percepção. (ABBAGNANO 1982, p. 115-116).

Em relação à definição do conceito, Abbagnano nos indica que o termo é um

signo do objeto (qualquer que seja) e se acha em relação de significação com ele; [uma das funções do conceito é a de] organizar os dados da experiência de modo que se estabeleçam entre eles conexões de natureza lógica. Um conceito científico, não se limita, via de regra, a descrever e classificar os dados empíricos, mas torna possível a sua derivação dedutiva. É esse o aspecto pelo qual a formulação conceitual das teorias científicas tende à axiomatização: a generalização e o rigor da axiomatização tende a levar ao limite o caráter logicamente organizador do conceito; são funções de organizar e de prever que exercem hoje os tipos fundamentais dos conceitos científicos que não são nem descritivos nem classificatórios: isto é, os modelos, os conceitos matemáticos e as construções. (ABBAGNANO, 1982, p. 153-156).

No entanto, ressaltamos que devido à proximidade e à relação entre categoria e conceito, esses termos são bastante confundidos na produção do conhecimento no campo das ciências humanas. Vejamos como a definição de conceito dividida em duas partes pode contribuir para a nossa compreensão sobre a teoria do conhecimento, pois Rickert afirma existirem dois tipos de conceitos:

conceitos simples e conceitos científicos. Os primeiros correspondem a elementos conceituais não definíveis (dados da percepção imediata, como as noções de "doce" ou "azul". Os conceitos científicos, por sua vez, são agregados - seja de elementos conceituais, seja de outros conceitos científicos. Para Rickert, não existe qualquer diferença entre o conteúdo de uma exposição científica, em geral, e o conteúdo do conceito. De modo que 'um complexo de conceitos, que encerra o conhecimento científico de uma realidade, é o conceito desta realidade (DA MATA, 2006, p. 355). 
A partir do exposto percebemos que Rickert ao classificar os conceitos em dois grupos indica que o primeiro são conceitos simples porque são dados da percepção imediata, não há o que questionar sobre a noção de doce. Enquanto que o segundo grupo está relacionado ao fazer científico e a realidade seria o próprio conceito dessa realidade.

Este ponto nos remete a questão dos valores na sua teoria do conhecimento, de forma geral, relativos às ciências da cultura ou ciências humanas; e de maneira específica, à história levando em consideração que a sua especificidade é que elas são indissociáveis dos valores sociais. Para Rickert há dois tipos de valoração: a teórica e a prática:

\begin{abstract}
A primeira permite ao historiador eleger o que, em meio à massa de objetos, épocas ou personalidades que tem diante de si, deve ser considerado efetivamente relevante. Claro está que se trata de um construto intersubjetivo, mas que não implica qualquer "tomada de posição". [...] Sem valoração teórica não há conceituação histórica [...]. Uma vez que sem ela não saberíamos sequer eleger o que é relevante. O problema da atribuição de historicidade é para Rickert - como o será para Weber - uma questão de valores "universais", isto é, socialmente partilhados. [A segunda] $A$ valoração prática, por seu turno, implica uma tomada de posição "contra" ou "a favor". Para ela não há, ao menos idealmente, lugar na ciência. A distinção entre estas duas modalidades pode ser ilustrada a partir de um exemplo dado por Rickert. Certamente concordaremos que há algo de errado com o historiador da arte caso ele só leve em conta em seus estudos aquilo que seu próprio gosto estabelece como "belo". Já o historiador científico "precisa se limitar ao que, contrariamente a uma valoração artística, podemos chamar de 'relação' teórica com o valor da arte" (DA MATA, 2006, p. 356).
\end{abstract}

A separação dos tipos de valoração entre teórica e prática exemplifica tanto a capacidade do ser humano em fazer leituras da realidade, ou seja, "teorizar" o mundo a sua volta; como ao mesmo tempo em que essa distinção da valoração demonstra, no tipo teórico, uma elaboração da elaboração na qual o que é teorizado cientificamente é selecionado do mundo fenomênico. Assim o conhecimento científico é engendrado no privilégio de certos fenômenos por meio do uso de conceitos em detrimentos de outros aspectos ou outros conceitos. 
Nesse viés, a produção de conhecimento nas ciências humanas ou nas ciências sociais deve ser construída levando em consideração entre os valores elencados pelos sujeitos da pesquisa (os sujeitos objetos de estudos) em decorrência de suas experiências ou vivencias, isto é, valorização prática; e as categorias, teorias e conceitos científicos que o pesquisador tem como background, ou seja, valorização teórica e suas categorias práticas também. Uma das especificidades das ciências humanas e ciências sociais em relação às ciências da natureza é que o nosso objeto de estudo é um ser pensante que constrói um conhecimento sobre o mundo e sobre a sua realidade.

Logo, como critério de objetividade, é importante se averiguar que conhecimento esse indivíduo traz para que possamos mapeá-los intersubjetivamente com outros sujeitos pesquisados e para que possamos construir o conhecimento sobre aquela realidade assumindo que é sempre uma leitura do mundo.

Essa valorização teórica é compreendida pelos neokatianos como a possibilidade do próprio pesquisador, seja da ciência da natureza ou das ciências humanas, só poder fazer leitura parcial e nunca total sobre o mundo, pois sua produção de conhecimento não tem como obter a essência do mundo. É nessa impossibilidade da produção do conhecimento em sua totalidade que a ciência se constitui como um campo de conhecimento não dogmático e sempre inacabado.

Assim, fazendo alguma comparação entre Popper e Rickert, ressaltamos que na teoria do conhecimento científico, para os neokantianos, o mundo fenomênico é percebido por meio de conceitos/teorias que possibilitam leituras do mundo, mas nunca o mundo em sua totalidade. Tal característica contribui para pensar as ciências ideográficas que procuram a percepção do particular, do que está relacionado com os juízos de valor que criam um mundo noumênico, a partir do mundo fenomênico e não necessariamente a refutabilidade das teorias.

Por outro lado, na construção da teoria do conhecimento proposta por Popper, a questão central está na refutabilidade e na impossibilidade de validar as leis científicas de forma conclusiva. Assim, como cada teoria ou proposição 
não pode ser comprovadamente admitida como verdadeira, elas são validadas a partir de suas capacidades de resistirem à refutabilidade.

O que nos leva a concluir que Popper lidava com uma frustração por não pode obter a verdade das coisas e dos fatos, como se ainda buscasse um exercício de abstração sobre a contingência e tal exercício seria materializado em uma metodologia comum para ambas as ciências (da natureza e da cultura ou do espírito).

Desta forma, haveria uma resignação e caberia ao cientista se contentar com a possibilidade da refutação como prêmio de consolação e tabua de salvação em um mar em fúria do mundo irracional e complexo.

Enquanto que para Rickert a impossibilidade de retratar o mundo fenomênico não era uma frustração, mas sim o que permitia sua especificidade, visto que a teoria do conhecimento científico se constrói por meio de entendimentos sobre entendimento já realizados, são interpretações das interpretações, são aspectos valorizados em detrimentos de outros aspectos. Esta perspectiva assume uma diferença metodológica entre as ciências humanas e as ciências sociais (kulturwissenschaften) que se dedicam ao que é singular e não pode ser repetido e as ciências naturais (naturwissenschaftlichen) que se debruçam sobre a investigação de leis gerais.

Desta maneira, o fazer da teoria do conhecimento tem a sua própria história que nos ajudar a entender/compreender os caminhos traçados e a construção de "verdades". Ou seja, necessitamos usar o verstehen na própria (re)construção da filosofia da ciência.

\section{Referências}

ABBAGNANO, Nicola. Dicionário de Filosofia. São Paulo: Mestre Jou, 1982.

BENTO, Ted. Philosophical Foudations of the Three Sociologies. Londres/ Henley/ Boston: Routledge e Kegan Oaul, 1977

CHALMERS, Alan F., O que é Ciência afinal? São Paulo: Brasiliense, 2000.

DA MATA, Sérgio. Heinrich Rickert e a fundamentação (axio)lógica do conhecimento histórico. 2006 
FEREREIRA, Jonatas. A Teoria do valor de Windelband e Rickert: fundamentos temporais de uma teoria do conhecimento in Estudos de Sociologia - Recife: Revista do PPGS da UFPE. Vol. 5, № 2. - 1999.

GIDDENS, Anthony - Política, Sociologia e Teoria Social: Encontros com o pensamento social clássico e contemporâneo. São Paulo: Unesp, 1998.

POPPER, Karl. A Lógica das Ciências Sociais. Rio de Janeiro e Brasília: Tempo Universitário/UNB, 1998.

OUTHWAITE, William. Entendendo a Vida Social. Brasília: Editora Universidade de, 1985.

\& Bottomore, Tom. Dicionário do Pensamento Social do Século XX. Rio de Janeiro: Jorge Zahar Editor, 1996.

RICKERT, Heinrich. The Limits of Concept Formation in Natural Science: A logical introduction to the historical sciences. Cambridge: Cambridge University Press, 1987. 